\title{
Perancangan Ruang Kerja dengan Konsep Nature Blend
}

\author{
Margiana Belinda Amaliya dan Collinthia Erwindi \\ Departemen Arsitektur, Fakultas Arsitektur, Desain dan Perencanaan, Institut Teknologi Sepuluh Nopember (ITS) \\ e-mail: c_erwindi@arch.its.ac.id
}

\begin{abstract}
Abstrak-Masyarakat pekerja di kota besar selalu disibukkan dengan deadline penyelesaian tugas dan tuntutan peran di tempat kerja sehingga membuat stres menjadi suatu faktor yang hampir tidak mungkin untuk dihindari. Stres kerja tidak hanya ditimbulkan karena beban kerja yang berat, namun juga pengaruh lingkungan kerja. Namun, kondisi dan suasana lingkungan kerja pada saat ini kurang memperhatikan kondisi kenyamanan dan psikologis pekerja. Keterikatan manusia dengan alam yang dijelaskan dalam ilmu biofilia memiliki manfaat, salah satunya dapat merespon stres. Oleh karena itu perancangan ini menawarkan lingkungan kerja yang membaur dengan alam (nature blend), yaitu dengan menghadirkan dan mendekatkan alam pada lingkungan kerja sehingga diharapkan nuansa alam dapat terasa saat bekerja. Konsep nature blend ini diharapkan dapat merespon masalah stres yang terjadi di tempat kerja.
\end{abstract}

Kata Kunci- biofilia, nature blend, lingkungan kerja, perkotaan, stres kerja.

\section{PENDAHULUAN}

$\mathrm{P}$ ADA tahun 2030, populasi masyarakat dunia akan berada di kota. Masyarakat perkotaan cenderung memiliki tuntutan hidup yang lebih tinggi dibandingkan dengan masyarakat pedesaan. Oleh karenanya masyarakat kota dituntut untuk berkerja keras memenuhi kebutuhan mereka.

Masyarakat pekerja di kota-kota besar seperti Jakarta, Surabaya, Yogyakarta yang sebagian besar merupakan urbanis dan industrialis yang selalu disibukkan dengan deadline penyelesaian tugas, tuntutan peran di tempat kerja yang semakin beragam dan kadang bertentangan satu dengan yang lain, masalah keluarga, beban kerja yang berlebihan, dan masih banyak tantangan lainnya yang membuat stres menjadi suatu faktor yang hampir tidak mungkin untuk dihindari.

Survey yang telah dilakukan Jobstreet menemukan bahwa $85 \%$ dari pada koresponden tidak memiliki work life dalam hidup mereka dan $62 \%$ karyawan tersebut mengaku sulit untuk tidur, dikarenakan masih memikirkan pekerjaannya di kantor.

Survey oleh Regus menyebutkan bahwa penyebab utama dari stres adalah pekerjaan. Hasil survey terkait stres dapat dilihat pada Gambar 1 sampai 3.

Beban kerja merupakan hal yang membuat karyawan stres dan jenuh. Namun ternyata terdapat hal lain yang juga mempengaruhi kondisi kantor sebagai tempat terjadinya stres kerja, yaitu kondisi lingkungan kerja itu sendiri.

Lingkungan kerja merupakan segala sesuatu yang ada disekitar para pekerja yang dapat mempengaruhi dirinya dalam mejalankan tugas yang dibebankan. Lingkungan Kerja terbagi menjadi lingkungan kerja fisik dan non fisik [1]. Dalam

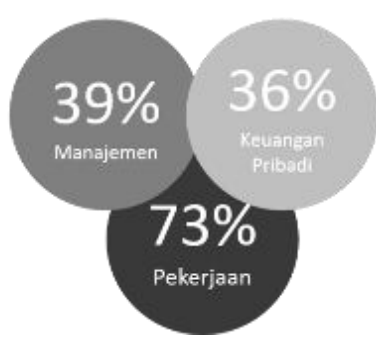

Gambar 1. Presentasi penyebab utama stress menurut survey yang dilakukan oleh Regus.

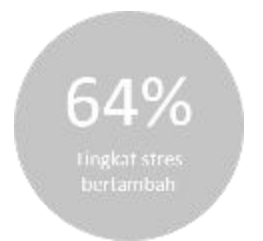

Gambar 2. Hasil survey Regus pada tahun 2012 mengenai tingkat stres terhadap enam belas ribu pekerja profesional di seluruh dunia.

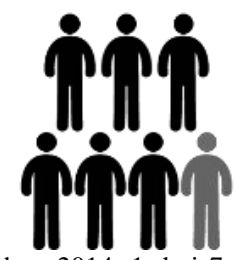

Gambar 3. Data WHO tahun 2014, 1 dari 7 orang mengalami gangguan kesehatan jiwa di kantor.

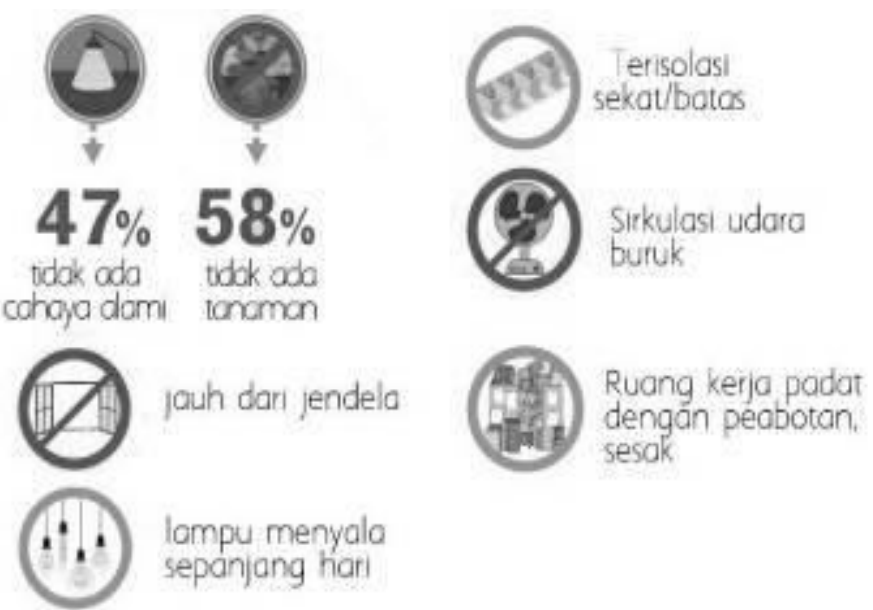

Gambar 4. Kondisi lingkungan kerja yang membuat stress.

konteks perancangan ini, hal yang disoroti adalah lingkungan kerja fisik. Lingkungan kerja sangat berpengaruh besar dalam pelaksanaan penyelesaian tugas. Kondisi lingkungan kerja fisik seperti suhu yang terlalu panas, terlalu dingin, terlalu sesak, 
Tabel 1.

Penelitian yang medukung biofilia dapat mengurangi stress

\begin{tabular}{cc}
\hline \hline Prinsip & Impact to Stress Reduction \\
\hline Visual & Lowered blood pressure and heart rate (Brown, Barton \& \\
Connection & Gladwell, 2013; van den Berg, Hartig, \& Staats, 2007; \\
with Nature & Tsunetsugu \& Miyazaki, 2005) \\
Thermal \& & Positively impacted comfort, well-being and productivity \\
Airflow & (Heerwagen, 2006; Tham \& Willem, 2005; Wigö, 2005) \\
Variability & \\
Presence of & Reduced stress, increased feelings of tranquility, lower \\
Water & heart rate and blood pressure \\
& (Alvarsson, Wiens, \& Nilsson, 2010; Pheasant, Fisher, \\
Wrospect & Watts et al., 2010; Biederman \& Vessel, 2006) \\
& Reduced stress \\
& (Grahn \& Stigsdotter, 2010) \\
\hline \hline
\end{tabular}

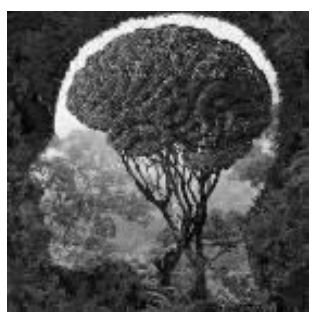

Gambar 5. Manusia memiliki keterikatan dengan alam.

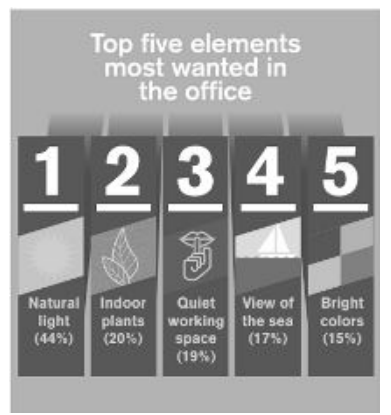

Gambar 6. Elemen yang diinginkan hadir di lingkungan kerja.

\begin{tabular}{|l|c|c|c|}
\hline \multirow{2}{*}{$\begin{array}{c}\text { How do you foel } \\
\text { when you enter the workplace'? }\end{array}$} & \multicolumn{2}{c|}{ Internal Green Space } \\
\cline { 2 - 4 } & Yas & No \\
\hline Positive & Happy & $15 \%$ & $9 \%$ \\
\hline Feelings & Inspired & $32 \%$ & $18 \%$ \\
\hline $\begin{array}{l}\text { Negative } \\
\text { Feelings }\end{array}$ & Anxious & $2 \%$ & $5 \%$ \\
\hline
\end{tabular}

Gambar 7. Tabel di atas menyajikan persentase responden $(\mathrm{N}=7600)$ yang melaporkan perasaan senang, terinspirasi, cemas atau bosan ketika memasuki tempat kerja yang menyediakan / tidak ruang hijau internal.

kurang cahaya, dapat mempengaruhi kondisi psikologis seseorang.

Kondisi lingkungan kerja fisik pada saat ini hanya terpaku kepada kebutuhan pekerjaan, namun kurang memperhatikan dampak psikologis pada pekerja, seperti yang terdapat pada Gambar 4 [2].

\section{METODE PERANCANGAN}

Manusia merupakan makhluk yang tidak dapat hidup sendiri, seperti yang dikatakan oleh Aristoteles dalam teorinya, Zoon Politicon. Hal tersebut dikarenakan adanya kebutuhan sosial untuk hidup berkelompok dengan orang lain. Oleh karena itu manusia selalu bergantung pada yang lain, tak
Tabel 2.

Penelitian yang medukung biofilia terhadap emosi, mood dan preferensi

\begin{tabular}{cc}
\hline \hline Prinsip & Impact to Emotion, Mood \& Preference \\
\hline Visual & Positively impacted attitude \\
Connection & and overall happiness \\
with Nature & (Barton \& Pretty, 2010) \\
Thermal \& & Positively impacted comfort, well-being and \\
Airflow & productivity \\
Variability & (Heerwagen, 2006; Tham \& Willem, 2005; Wigö, 2005) \\
Presence of & Reduced stress, increased feelings of tranquility, lower \\
Water & heart rate and blood pressure \\
& (Alvarsson, Wiens, \& Nilsson, 2010; Pheasant, Fisher, \\
Prospect & Watts et al., 2010; Biederman \& Vessel, 2006) \\
& Reduced stress \\
& (Grahn \& Stigsdotter, 2010) \\
\hline \hline
\end{tabular}

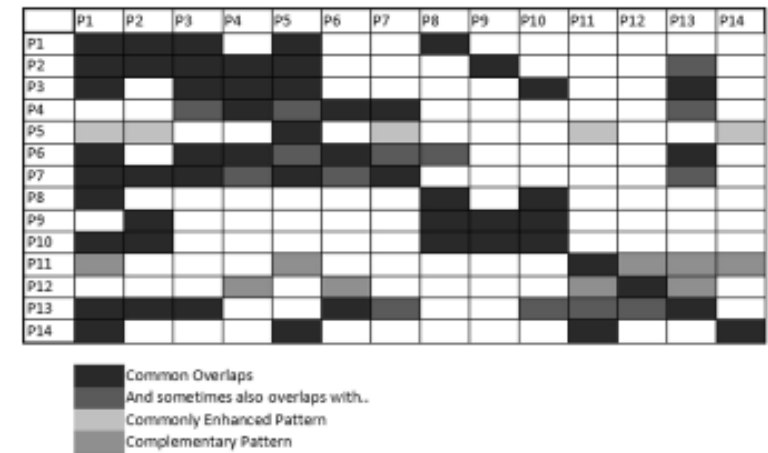

Gambar 8. Tabel di atas menyajikan hubungan antar prinsip biofilia.

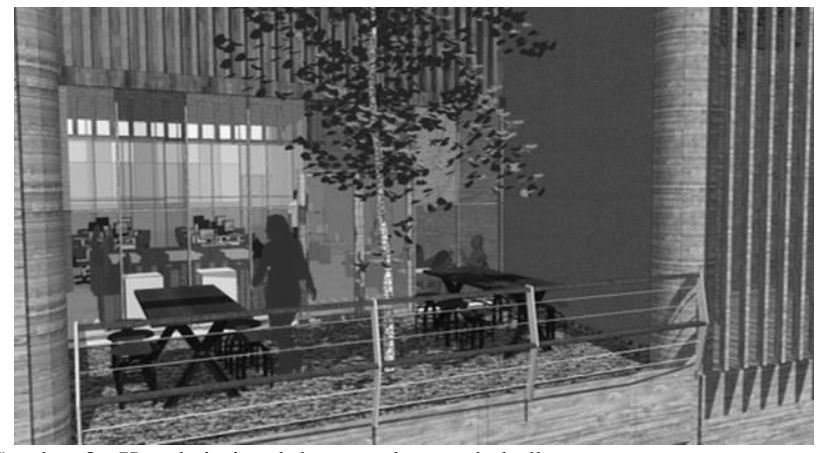

Gambar 8. Koneksi visual dengan alam pada balkon.

terkecuali pada lingkungan di sekitarnya. Seperti misalnya pada jaman dahulu, manusia bergantung pada alam untuk memenuhi kebutuhan dan kelangsungan hidupnya. Kontak dengan alam merupakan kebutuhan manusia.

Fakta mengenai kebutuhan manusia akan alam juga dibuktikan oleh sebuah penelitian. Sebuah penelitian di Singapura dalam buku Futurarc: The Biophilic Space melibatkan 2000 pegawai dari 11 kantor [3]. Survey yang dilakukan adalah dengan menanyakan fitur apa yang diinginkan oleh pekerja sehingga dapat mengurangi stres yang terjadi di tempat kerja. Hasil survey menyebutkan 4 dari 9 jawaban mengacu pada elemen yang terdapat di alam. Berikut adalah hasil survey:

1) Tanaman Hijau

2) View ke luar

3) Cahaya Alami

4) Air

5) Kualitas Udara 


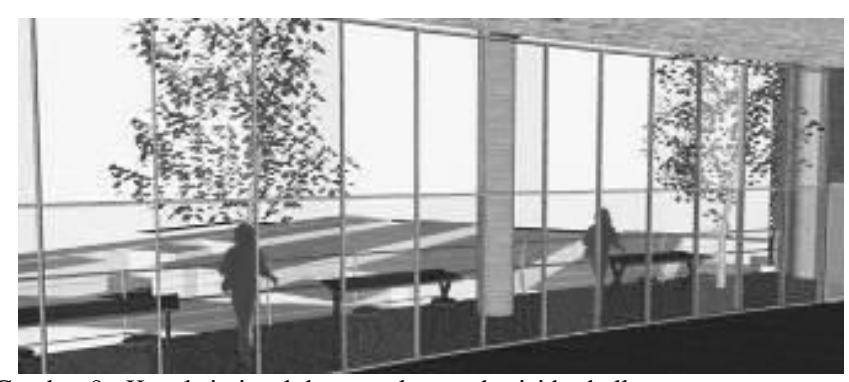

Gambar 9. Koneksi visual dengan alam pada sisi berbalkon.

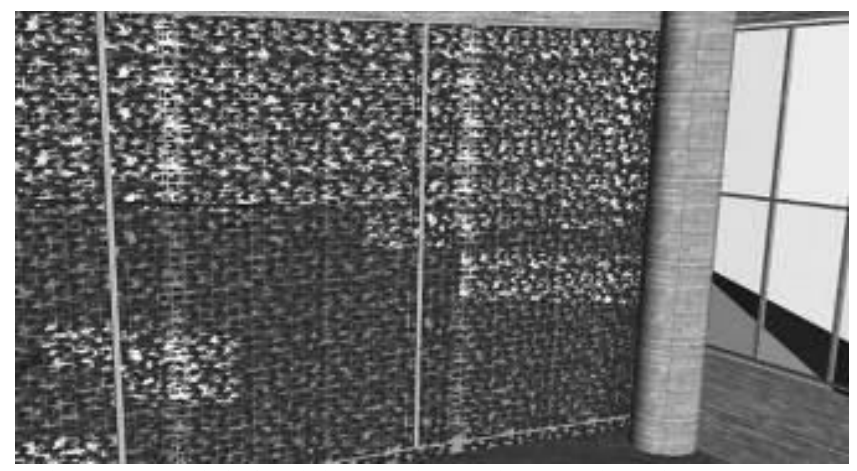

Gambar 10. Koneksi visual dengan alam pada secondary skin.

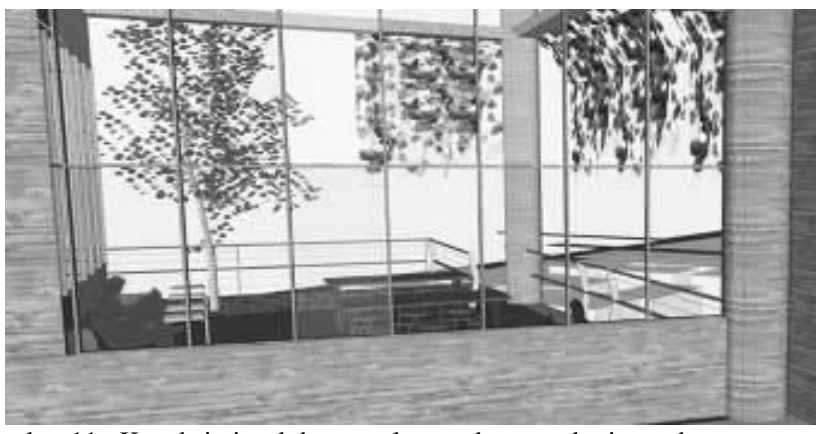

Gambar 11. Koneksi visual dengan alam pada ruang kerja outdoor.

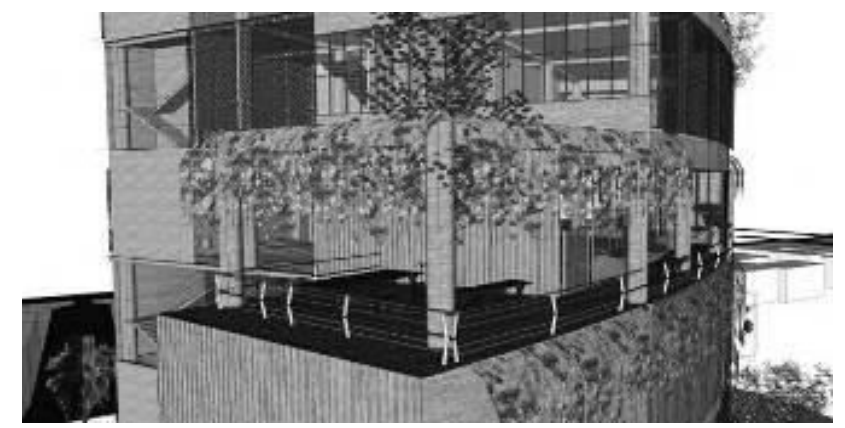

Gambar 12. Koneksi visual dengan alam dengan tanaman gantung.

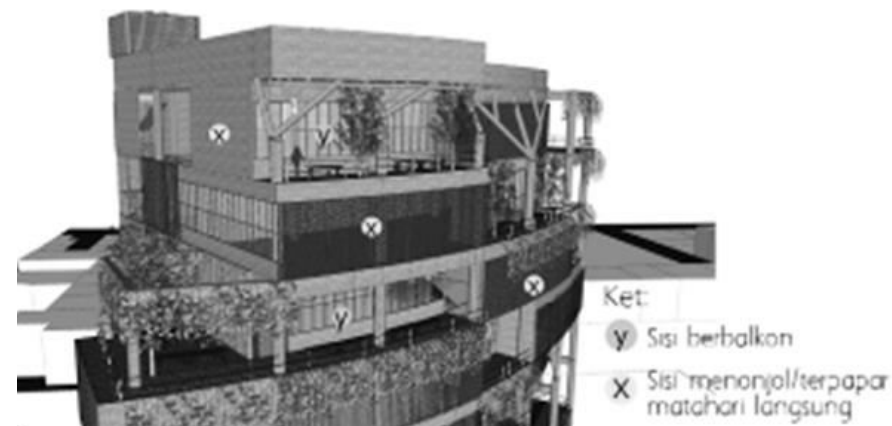

Gambar 13. Perletakan sisi berbalkon dan sisi yang terpapar sinar matahari secara langsung.

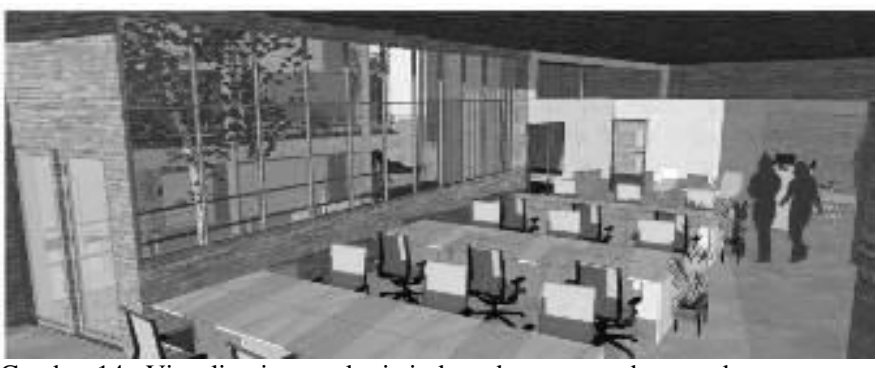

Gambar 14. Visualisasi ruang kerja indoor dengan penghawaan buatan.

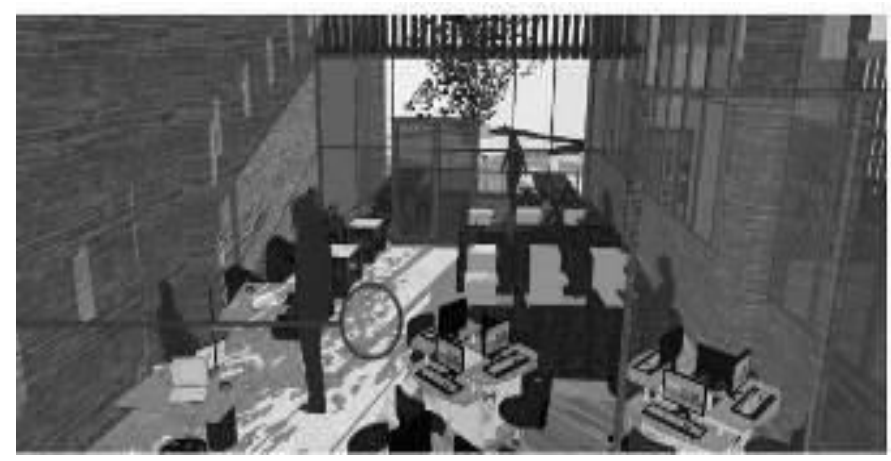

Gambar 15. Visualisasi ruang kerja indoor dengan penghawaan alami.

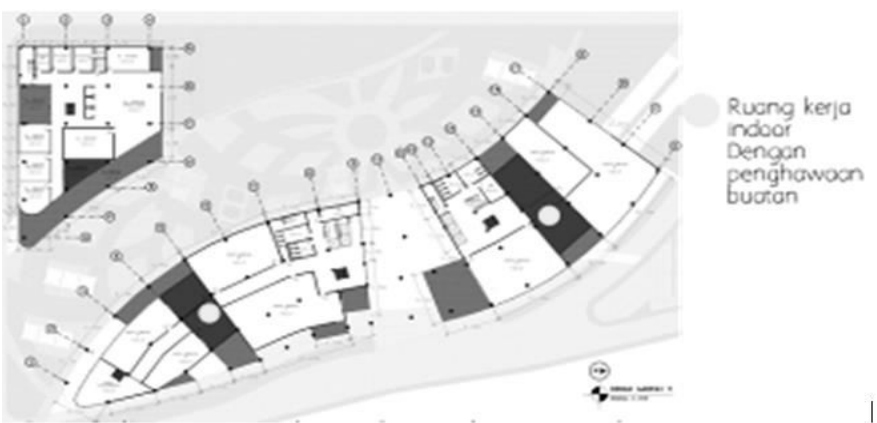

Gambar 16. Letak ruang kerja indoor dengan penghawaan buatan.

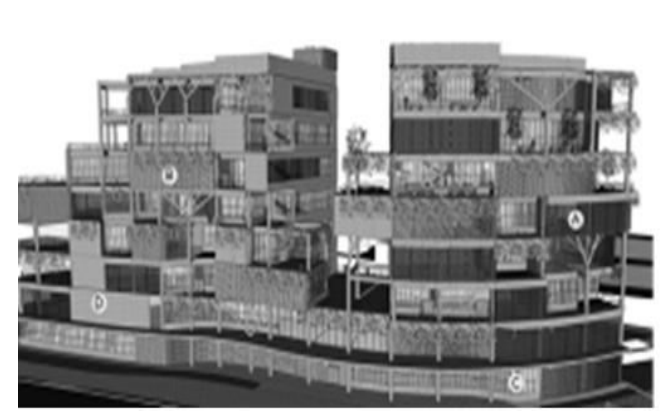

Material Fasad:

A Groen scoondarystin

B Kisi-bisikay

C Kaco

o Claddingkay

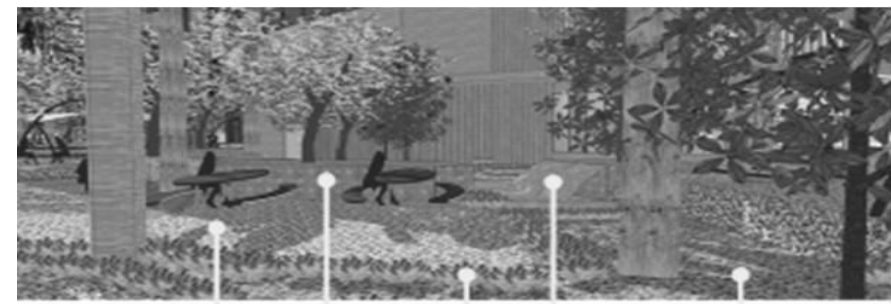

PAVERS DRIVEWAY BRICK

PATU

BUNGA LAVENDER

RUMPUT

Gambar 18. Material lansekap. 


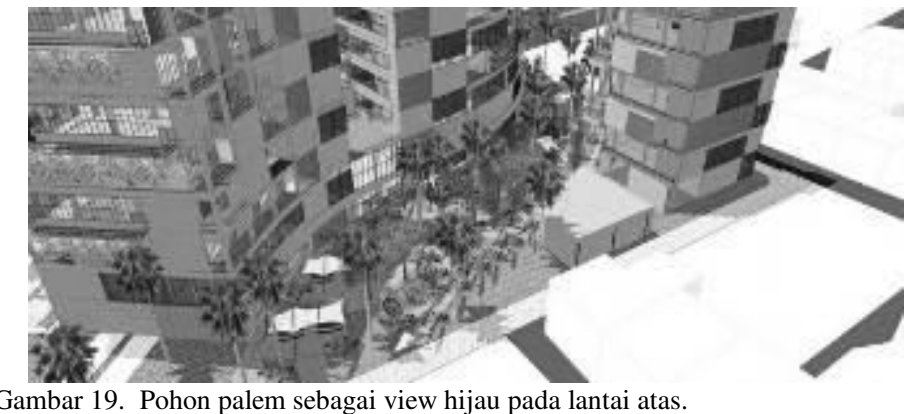

Gambar 19. Pohon palem sebagai view hijau pada lantai atas.

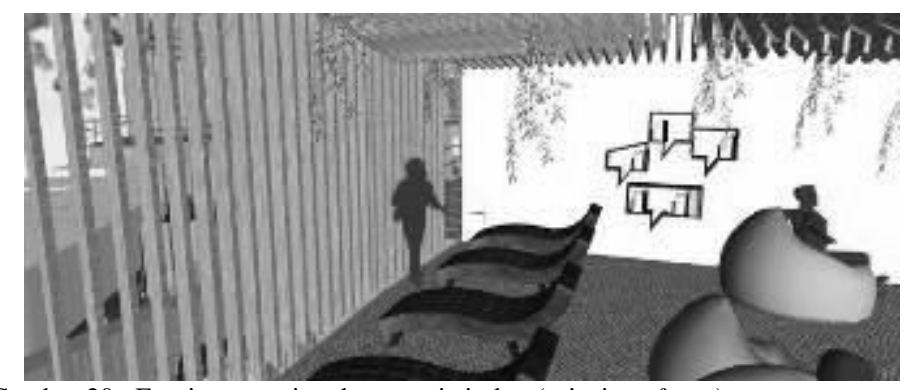

Gambar 20. Furnitur santai pada ruang istirahat (prinsip refugee).

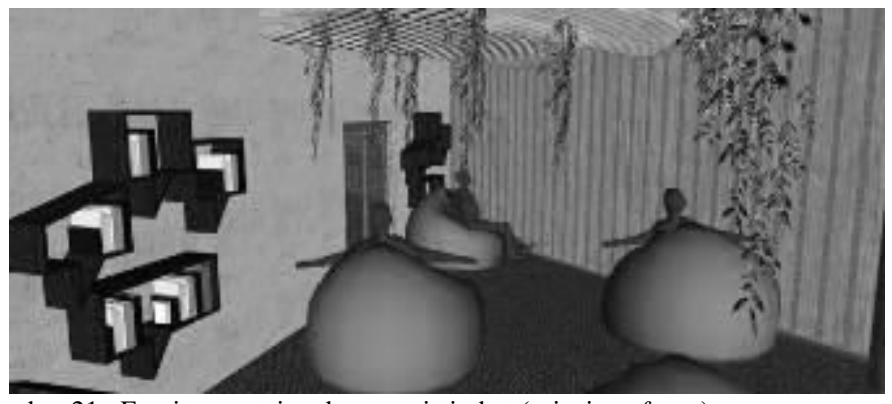

Gambar 21. Furnitur santai pada ruang istirahat (prinsip refugee).

6) Kontrol Suhu

7) Kebersihan

8) Privasi

9) Kontrol Suara

Pada Gambar 5 juga menyebutkan elemen yang paling diingiinkan pekerja di kantor [2]. Dari analisa mengenai keterkaitan dan kebutuhan antara manusia dengan alam dapat ditentukan pendekatan yang akan digunakan pada rancangan ini. Pendekatan yang akan digunakan untuk mengatasi masalah stres pada lingkungan kerja adalah pendekatan manusia dengan alam yang dikenal dengan ilmu biophilic.

Keterikatan manusia dengan alam dijelaskan oleh Stephen Kellert dalam bukunya yang berjudul The Practice of Biophilic Design, yang dikenal dengan ilmu biophilia, yaitu secara lahiriyah manusia memiliki kecenderungan dengan alam. Kecenderungan tersebut memiliki beberapa manfaat, yaitu dapat mengatasi stres, meningkatkan performa kognitif, memiiki efek positif terhadap suasaa hati dan emosi [4]. (Tabel 1 dan 2)

Manfaat yang dihasilkan dari keterikatan antara manusia dan alam kemudian dijadikan sebagai pendekatan dan metode untuk menangani masalah stres pada lingkungan kerja.

Dalam buku 14 Pattern of Biophilic Design, prinsip biofilia terbagi menjadi 3 kategori dan memiliki 14 prinsip. Yaitu:
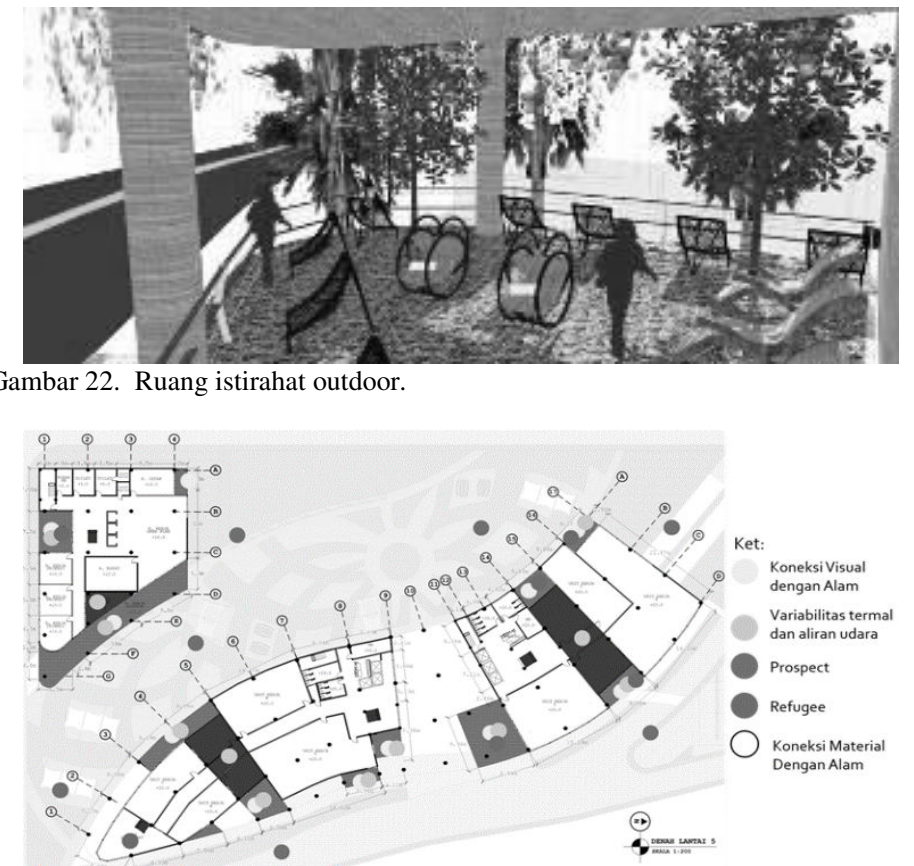

Gambar 23. Penerapan prinsip biofilia pada rancangan.

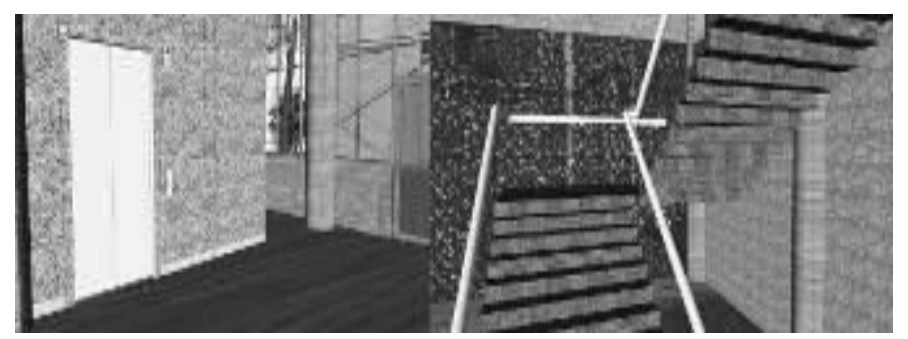

Gambar 24. Material pada sirkulasi vertical.

\section{A. Nature in The Space}

Menghadirkan unsur alam secara langsung ke dalam sebuah ruang atau tempat. Secara fisik dan dalam kurun waktu tertentu. Seperti tumbuhan, hewan, air, suara, aroma dan elemen alam yang lainnya.

Prinsip desain pada kategori ini yaitu:

1. Visual Connection with Nature

2. Non-Visual Connection with Nature

3. Non-Rhythmic Sensory Stimuli

4. Thermal \& Airflow Variability

5. Presence of Water

6. Dynamic \& Diffuse Light

7. Connection with Natural Systems

B. Natural Analogues

Membahas kehadiran alam secara organik dan tidak hidup dengan menyediakan informasi tentang alam yang terorganisasi dengan baik. Prinsip desain pada kategori ini yaitu:

\section{Biomorphic Forms \& Patterns}

2. Material Connection with Nature

3. Complexity \& Order

4. Nature of The Space

Membahas konfigurasi spasial di alam. Termasuk keinginan untuk dapat mempelajari alam, melihat melampaui lingkungan sekitar. Prinsip desain pada kategori ini yaitu: 
1. Prospect

2. Refugee

3. Mystery

4. Risk/Peril

Namun tidak semua prinsip biofilia diterapkan ke dalam rancangan karena dari 14 prinsip biophilic tersebut, terdapat beberapa prinsip yang saling tumpang tindih (overlaps) satu sama lainnya, terdapat pula prinsip yang sebaiknya diimbangi dan sebaiknya dilengkapi oleh prinsip lainnya.

Pada Gambar 8 dapat dilihat prinsip-prinsip yang saling tumpang tindih maupun prinsip yang sebaiknya dilengkapi dengan prinsip lainnya.

Dari diagram tersebut diputuskan prinsip yang akan diterapkan sebagai metode ke dalam rancangan. Yaitu prinsip P1 koneksi visual dengan alam, P4 variabilitas termal dan aliran udara, P9 koneksi material dengan alam, P11 prospect dan P12 refugee.

Prinsip 1 digunakan karena banyak memiliki overlaps dengan prinsip yang lainnya. Selain itu, prinsip ini juga didukung oleh data empiris yang kuat, memiliki kuantitas dan kualitas bukti yang kuat dan berpotensi memiliki dampak yang besar terhadap stres. Prinsip-prinsip lain yang tidak tercakup atau tidak tumpang tindih dengan prinsip P1 (P4, P9, P11 dan $P 12)$ akan diterapkan ke dalam rancangan dengan tujuan agar membauran alam (nature blend) dengan lingkungan kerja serta nuansa alam dapat dirasakan secara maksimal oleh pengguna.

\section{HASIL PERANCANGAN}

\section{A. Eksplorasi Formal}

\section{Koneksi Visual dengan Alam (P1)}

Merupakan adanya pandangan terhadap unsur alam, sistem kehidupan dan proses alam secara langsung ke dalam sebuah ruangan, sehingga suatu ruang dapat menunjukkan waktu, keadaan cuaca dan makhluk hidup yang lain.

Pengaplikasian ke dalam bangunan adalah menghadirkan lingkungan yang membantu individu untuk merilekskan otot mata dan kelelahan kognitif serta cara meletakkan ruangan di dekat ruang hijau. Lingkungan tersebut dapat dihadirkan secara alami / natural maupun buatan. (Gambar 9-12) Berikut ini penerapan pada perancangan:

1. Tiap unit kantor sewa memiliki view terhadap greenery

2. Menghadirkan tanaman dan air ke dalam bangunan

3. Memperbanyak penggunaan bukaan dan material transparan

4. Semua massa bangunan menghadap taman

5. Mendekatkan dan menghadirkan vegetasi ke dalam bangunan sehingga tercipta suasana outdoor pada balkon maupun dengan secondary skin.

Efek dari prinsip ini ke dalam bentuk bangunan adalah adanya fasad yang menonjol dan yang tercoak (berbalkon). (Gambar 13)

\section{Variabilitas Panas dan Aliran Udara}

Penelitian menunjukkan bahwa manusia tertarik pada lingkungan yang berubah-ubah, seperti variasi dalam cahaya, suara dan suhu.
Pengaplikasian pada perancangan adalah dengan menyediakan ruang kerja dengan penghawaan buatan, penghawaan alami, dan outdoor sertan menggunakan pencahayaan alami. Elemen-elemen dari prinsip ini adalah:

Alami : panas matahari, bayangan dan naungan, orientasi ruang.

Buatan : strategi penghantaran HVAC, kontrol sistem, pelapisan dan perlakuan khusus terhadap kaca, operasional jendela dan ventilasi cross.

Penerapan dapat dilihat pada Gambar 14-16.

\section{Koneksi Material dengan Alam}

Material dan elemen berasal dari alam atau menyerupai mencerminkan ekologi atau geologi setempat dan menciptakan rasa tempat yang berbeda. Material alami dapat dihadirkan dengan cara bersifat dekoratif atau fungsional, seperti:

Pada perancangan, prinsip ini dihadirkan dengan cara: (Gambar 17-18)

a) Menggunakan material alami seperti kayu dan batu pada fasad maupun sebagai pelapis dinding dan lantai.

b) Menggunakan warna-warna yang terdapat di alam seperti warna coklat (kayu), abu-abu (batu), hijau (tanaman), biru (langit) pada dinding dan fasad bangunan.

\section{Prospect}

Pandangan jarak jauh tanpa halangan dengan tujuan pengawasan/perencanaan agar pengguna dapat melihat-lihat dan merenungkan lingkungan disekitarnya. Tempat dengan prospect yang baik akan memberikan rasa terbuka dan bebas.Tujuan dari prinsip ini adalah untuk memberi pengguna kondisi yang sesuai melihat-lihat dan merenungkan lingkungan sekitar. Penerapan prinsip ini pada perancangan adalah:

a) Memperhatikan orientasi bangunan, koridor dan workstation terhadap akses visual ke pemandangan tanaman.

b) Membuat lansekap di tengah-tengah site sebagai pemisah massa sehingga tercipta jarak yang jauh.

c) Menanam beberapa tanaman tiggi seperti pohon palm pada lansekap sebagai view dari lantai atas (Gambar 19).

Elemen-elemen dari prinsip ini adalah:

$$
\begin{array}{ll}
\text { Atribut Spasial: } & - \text { Focal length } \geq 20 \text { kaki }(6 \text { meter }) \\
& - \text { Ketinggian partisi } \leq 42 \text { inci } \\
\text { Fitur umum : } & \text { - Menggunakan bahan transparan } \\
& - \text { Menyediakan balkon } \\
& \text { - Open floor plan } \\
& \cdot \text { Elevated planes } \\
& - \text { View termasuk pohon peneduh, air }
\end{array}
$$

\section{Refugee}

Tempat untuk menghindarkan diri dari lingkungan/suatu kegiatan di lingkungan dimana individu akan merasa terlindungi. Tujuannya adalah untuk menyediakan lingkungan yang mudah diakses dan memberi perlindungan bagi pengguna. Selain itu juga untuk membatasi akses visual ke dalam ruang perlindungan.

Penerapan prinsip ini pada rancangan adalah menyediakan fasilitas maupun tempat untuk menghindarkan diri dari lingkungan / suatu kegiatan dengan tujuan untuk beristirahat sejenak maupun untuk bekerja yang membutuhkan konsentrasi tinggi, yaitu: 


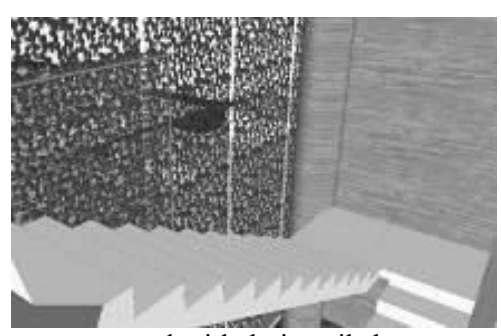

Gambar 25. View greenery pada sirkulasi vertikal.

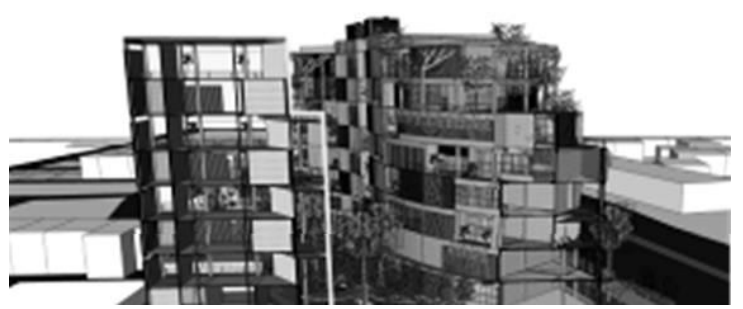

Gambar 26. Material batu alam pada sirkulasi vertikal

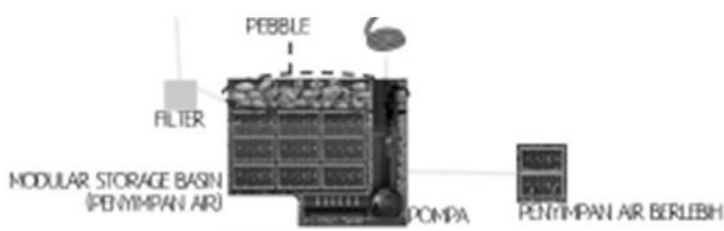

Gambar 26. Penerapan rainwater harvesting pada water feature.

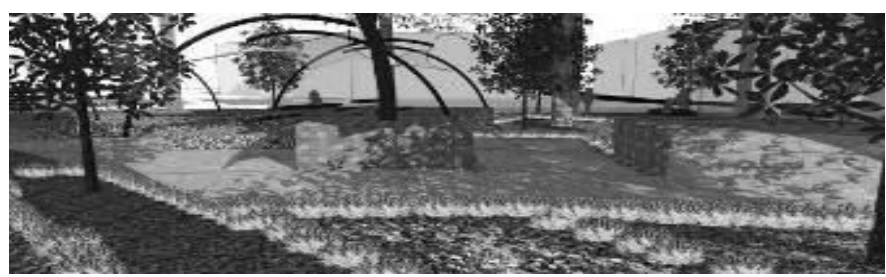

Gambar 27. Kolam dari rainwater harvesting.

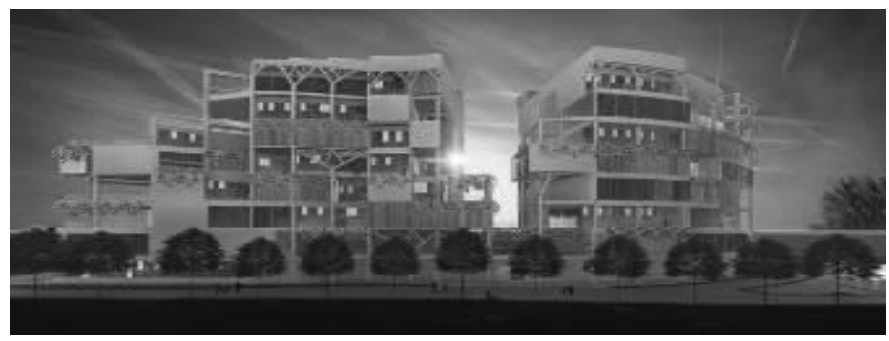

Gambar 28. Perspektif.

a) Pada tiap lantai terdapat ruang istirahat/tidur siang

b) Ruang istirahat berisi berbagai macam bentuk furniture yang nyaman agar pekerja dapat mengistirahatkan tubuhnya.

c) Ruang istirahat memiliki view menuju taman. (Gambar 20-22)

\section{B. Eksplorasi Teknis}

1) Sirkulasi Vertikal

Sesuai dengan konsep besar nature blend, material yang digunakan untuk tangga adalah batu alam andesit berwarna abu-abu. Sedangkan untuk lift, material yang digunakan untuk mencerminkan alam adalah dengan melapisi sisi lift dengan cladding batu. (Gambar 24)

\section{2) Tangga Darurat}

Tangga darurat diselubungi oleh material tahan api. Material yang digunakan pada beberapa sisi ruang tangga darurat adalah kaca tahan api yang sehingga ketika terjadi kebakaran, pengguna bangunan tidak merasa panik karena terkurung dalam bangunan karena terdapat cahaya yang masuk dari luar ke tangga darurat. (Gambar 25)

\section{3) Rain Water Harvesting}

Sistem pengolahan air hujan digunakan sebagai salah satu fitur air pada lansekap yang ada di antara 2 massa bangunan. Air hujan kemudian akan mengalir pada talang-talang air yang letaknya disesuaikan dengan dengan letak kolom struktur bangunan. Air dari talang tersebut kemudian bermuara pada bak yang terkubur didalam tanah. Bak pertama ini berfungsi menyaring/filter air. Bak kemudian dihubungkan oleh pipa kepada bak penyimpan air yang berjumlah banyak (modular storage basin). Air di dalam modular storage basin dapat digunakan untuk menyiram tanaman maupun membentuk kolam diatasnya dengan bantuan pompa.

Material hardscape pada lansekap pada sisi selatan menggunakan batu pebble. Letak batu berpori ini dapat meresap air hujan dan kemudian menyalurkannya kedalam modular storage basin untuk digunakan kembali.

(Gambar 26-27)

\section{4) Struktur}

Rancangan menggunakan sitem struktur kolom dan balok karena beberapa titik kolom pada rancangan dibuat menggunakan kolom berbentuk $\mathrm{Y}$ yang kemudian dibuat menyerupai pohon (metafora).

\section{KESIMPULAN}

Stres kerja berhubungan dengan kondisi lingkungan kerja yang ada di sekitar pekerja, baik fisik maupun non fisik. Buruknya kondisi lingkungan kerja yang ada pada perkantoran pada saat ini menyebabkan masalah kesehatan psikologis pekerja, yaitu stres. Dengan demikian, objek rancang berupa ruang kerja yang dekat dengan alam dan menyediakan fasilitas istirahat dan pelepas penat bagi pekerja diajukan untuk mengatasi masalah tersebut.

Perancangan ruang kerja dengan konsep nature blend ini menggunakan pendekatan desain biofilia dan menerapkan beberapa prinsip dari biofilia seperti koneksi visual dengan alam, variabilitas termal dan aliran udara, koneksi material dengan alam, prospect dan refugee. Pemilihan prinsip tersebut untuk dijadikan metode adalah karena prinsip koneksi visual dengan alam memiliki hasil penelitian yang paling kuat untuk merespon stress, sementara ke 4 lainnya adalah prinsip yang berbeda (tidak tumpang tindih) dengan prinsip konneksi visual sehingga diharapkan alam (nature) dapat secara maksimal didekatkan/ dibaurkan (blend) pada desain ruang kerja.

Kehadiran alam yang dekat dengan ruang kerja diharapkan menjadi sarana healing dan inspirasi bagi para pekerja. Selain itu, disediakannya beberapa fasilitas hiburan pada rancangan juga diharapkan menjadi sarana yang dapat melepas penat sejenak bagi para pegawai sehingga para pekerja tidak sampai stres dalam melakukan pekerjaan mereka. 


\section{DAFTAR PUSTAKA}

[1] D. Septianto, "Pengaruh Lingkungan Kerja dan Stres Kerja Terhadap Kinerja Karyawan,” Semarang, 2010.

[2] B. Browning and C. Cooper, "The Global Impact of Biophilic Design in The Workplace," New York, 2015.
[3] N. Kishnani, FuturArc: The Biophilic Space. 2015.

[4] W. D. Browning, C. O. Ryan, and J. O. Clancy, 14 Patterns Of Biophilic Design: Improving Health \& Well-Being In The Built Environment. New York: Terrapin Bright Green, LLC, 2014. 